\title{
Impact of a community-based bug-hunting campaign on Chagas disease control: a case study in the department of Jalapa, Guatemala
}

\author{
Kota Yoshioka/ ${ }^{+}$ \\ Chagas Disease Control Project, Japan International Cooperation Agency, Managua, Nicaragua
}

\begin{abstract}
Chagas disease control requires an innovative approach to strengthen community participation in vector surveillance. This paper presents a case study of a community-based bug-hunting campaign in Guatemala. The campaign was implemented in 2007 in the following three stages: (i) a four week preparation stage to promote bug-hunting, (ii) a one week bug-hunting stage to capture and collect bugs and (iii) a 10 week follow-up stage to analyse the bugs and spray insecticide. A total of 2,845 bugs were reported, of which 7\% were Triatominae vectors, such as Rhodnius prolixus and Triatoma dimidiata. The bug-hunting campaign detected a five-six-fold higher amount of vectors in one week than traditional community-based surveillance detects in one year. The bug-hunting campaign effectively detected vectors during a short period, provided information to update the vector infestation map and increased community and political awareness regarding Chagas disease. This approach could be recommended as an effective and feasible strategy to strengthen vector surveillance on a larger scale.
\end{abstract}

Key words: Chagas disease - health campaigns - community participation - Rhodnius prolixus - Triatoma dimidiata - Guatemala

Chagas disease is a parasitic disease that affects the rural populations of Latin America. Vectors from the subfamily Triatominae are primarily responsible for human infection with the causal agent, Trypanosoma cruzi. Interruption of domestic vector-borne transmission by 2015 has been proposed internationally (WHO 2012). In the 21 endemic counties in Latin America, the estimated annual incidence has decreased drastically from 700,000 in 1990 to 41,200 in 2006 (Dias 2009), which is primarily a result of vector control and blood donor screening (Moncayo \& Silveira 2009). However, vector-borne transmission persists and there is a need to establish constant vector surveillance systems (Hashimoto \& Yoshioka 2012).

Currently, the central strategy for vector surveillance is community-based vector reporting and selective vector control, such as insecticide spraying (Schofield \& Dias 1999, Schofield et al. 2006). However, in endemic countries, the national vector control programs have been facing financial and managerial challenges to longterm implementation of vector surveillance over large areas. In regions where the health systems are decentralised, the vector control programs are often underfunded and fragmented (Yadón et al. 2006). Furthermore, the vector surveillance systems only cover limited areas, especially against widespread autochthonous vectors and fail to maintain political will or community interest. The loss of coverage or interest could lead to a recurrence of domestic vector-borne transmission. To establish effective surveillance, an innovative vector control approach is necessary (Nakagawa 2009).

+ Corresponding author: yoshiokakota@gmail.com

Received 23 June 2012

Accepted 30 November 2012
Campaigns are a commonly used approach for public health programs, but the term "campaign" has many different meanings. Mass-media campaigns are used for zinc promotion (Wang et al. 2011), tobacco control (Hill $\&$ Carroll 2003) or human immunodeficiency virus/acquired immune deficiency syndrome prevention (Farr et al. 2005) and are likely to change the knowledge or behaviour of the target populations (Randolph et al. 2012). Mass distribution of public health tools, such as vaccines or insecticide-treated bed nets, is also considered an effective campaign method (Skarbinski et al. 2007, Thwing et al. 2008, Terlouw et al. 2010). To control vector-borne diseases, community-based vector control through intensive educational campaigns are currently being used for lymphatic filariasis (Nandha \& Krishnamoorthy 2011) and dengue fever (Johnson 2002, Pai et al. 2006, Shriram et al. 2009). To control Chagas disease, the term "campaign" has been used for massive vector control operations that include insecticide spraying (Ceballos et al. 2011, Silveira \& Dias 2011). In general, a "campaign" seems to imply an intensive intervention that aims to deliver information, tools or services to a large population in a short time with the expectation that changes in community health-status will occur.

This paper recommends a community-based bughunting campaign as an innovative approach for the control of Chagas disease. A bug-hunting campaign in Guatemala will be described and examined as a case study. The impact of the bug-hunting campaign and political opportunities for large-scale implementation will be discussed.

\section{MATERIALS AND METHODS}

Location of the bug-hunting campaign - The campaign was implemented in San Pedro Pinula, which is one of the seven municipalities of the department of Jalapa, Guatemala (Fig. 1). San Pedro Pinula consists of 71 communities and is located between $14^{\circ} 33^{\prime} 14^{\circ} 53^{\prime} \mathrm{N}$ and $89^{\circ} 43^{\prime}$ 
89 58' W. San Pedro Pinula is located between 990-1,900 $\mathrm{m}$ above sea level (masl). The population size is 43,092 and 9,132 houses are located in the region (INE 2002).

In 2000-2001, the Ministry of Health (MoH) of Guatemala conducted an entomological baseline survey in 64 communities of San Pedro Pinula, which are located under 1,600 masl, using the man-hour manual search method (Schofield 2001). The baseline survey found that $23.4 \%(15 / 64)$ of the communities were infested with Rhodnius prolixus and that $59.4 \%$ (38/64) of the communities were infested with Triatoma dimidiata. The percentage of infested houses was 3.9\% (23/584) for $R$. prolixus and $11.5 \%(67 / 584)$ for $T$. dimidiata. In all of the infested communities, more than $90 \%$ of the existing houses were sprayed at least twice till 2005.

Community-based vector surveillance was implemented gradually starting in 2004, with promotional activities targeting schoolchildren, community leaders and community health volunteers. $\mathrm{MoH}$ vector control personnel visited homes that were reportedly infested and conducted entomological investigations. If nymph or female $T$. dimidiata were found, the houses were sprayed with insecticide. For instance, in 2006, 19 specimens of T. dimidiata were reported from 13 houses in San Pedro Pinula. In response, all houses were investigated and four were sprayed. No $R$. prolixus specimens had been observed until a villager reported re-infestation in June of 2007. A bug-hunting campaign was implemented in $\mathrm{Au}-$ gust 2007 that targeted all 71 communities in San Pedro Pinula, regardless of previous vector infestation history.

Process of implementation - The "Chagas Week" campaign was designed with two main objectives: (i) detect $R$. prolixus and (ii) detect $T$. dimidiata. The central strategy was for inhabitants of the community to perform intensive bug-hunting in their houses. For community mobilisation, various stakeholders, such as the $\mathrm{MoH}$ health personnel, community health volunteers, schoolteachers and non-governmental organisation (NGO) workers, were involved in promotional activities. Chagas Week was implemented between 20-24 August 2007; the preceding four weeks were used as a prepara-

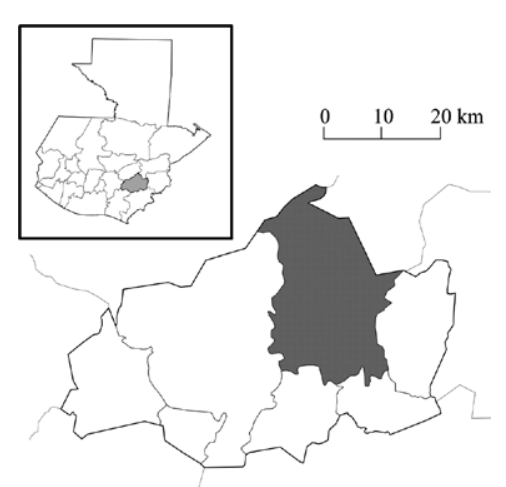

Fig. 1: geographical location of the municipality of San Pedro Pinula (dark shaded), department of Jalapa, southeast of Guatemala (see inset map). tion stage and a follow-up stage was conducted during the following 10 weeks.

During the preparation stage, the main task was intersectoral coordination and knowledge dissemination to raise community participation in the bug-hunting campaign. The campaign was managed and coordinated by the following three managers at the Guatemalan $\mathrm{MoH}$ : the departmental health director, the chief of the vector control unit in the departmental health office and the municipal health coordinator (Fig. 2). A volunteer from the Japan International Cooperation Agency provided technical and managerial support during proposal writing, planning of the campaign process, communication between the three managers and data management.

After the departmental health director approved the proposal with financial commitment, the municipal health coordinator organised various agencies at the municipal level, such as the MoH health centres/posts, NGOs, municipal governments and municipal offices of the Ministry of Education. A total of 525 intermediate agents participated in the campaign, including nine staff from the MoH health centres/posts, 21 staff and 129 community health facilitators from a local NGO, 40 community political leaders, 76 community health volunteers, 230 primary school teachers and 20 rural development facilitators from an international NGO.

The chief of the vector control unit held seven seminars for the intermediate agents to provide the participants with basic information about Chagas disease and the procedures of bug reporting. The vector control unit provided the intermediate agents with a total of 15,000 material packages that contained letter-size promotional flyers, bug reporting forms, lottery tickets and plastic bags for capturing the bugs. The intermediate agents distributed the flyers and plastic bags in their communi-

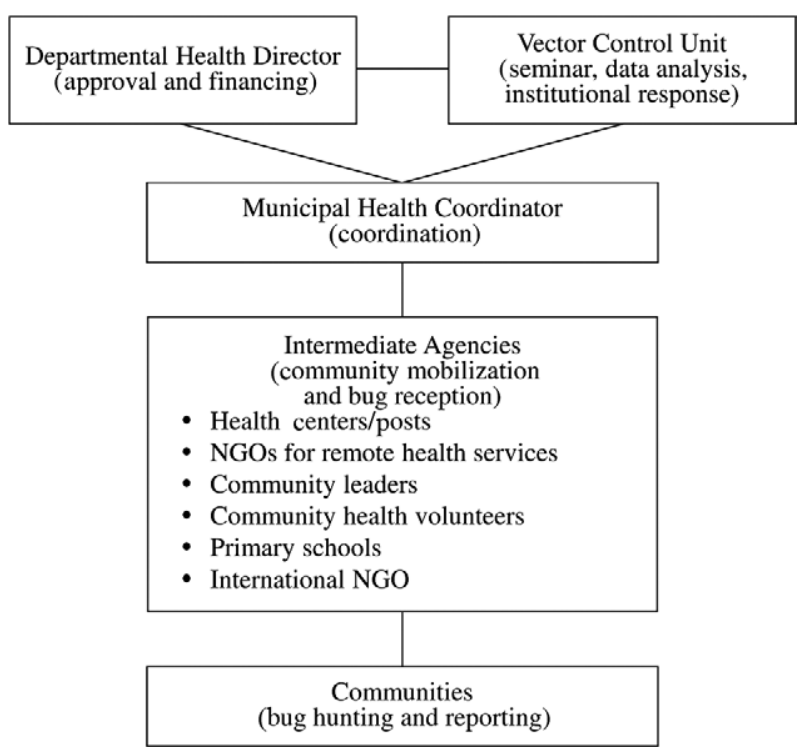

Fig. 2: organization to implement the bug-hunting campaign "Chagas Week" in the municipality of San Pedro Pinula, department of Jalapa, Guatemala, 2007. NGO: non-governmental organization. 
ties with the slogan, Busque la chinche picuda y gane su premio (Look for kissing bugs and win your prize) to inform community inhabitants of the campaign.

The schoolteachers gave a lesson to schoolchildren and the community leaders or health volunteers visited homes to encourage residents to look for bugs. The institutional staff from the $\mathrm{MoH}$ and NGOs provided information about the campaign when they had contact with community inhabitants during their daily work routines. Additionally, six staff from the vector control unit visited all 78 existing primary schools and set up "bug reporting boxes" in which schoolteachers could keep the captured bugs.

During Chagas Week, community inhabitants searched for bugs in their houses. The community inhabitants were encouraged to capture all suspicious bugs in the plastic bags and to hand the captured bugs to accessible intermediate agents, such as community health volunteers, community leaders, community health facilitators from NGO's and schoolteachers. The intermediate agents recorded the collected data on the bug reporting forms and exchanged the captured bugs for lottery tickets. The community health volunteers and leaders then transported the bugs to the $\mathrm{MoH}$ municipal health centre. The community health facilitators from the NGOs forwarded the bugs to the NGO departmental office. The schoolteachers deposited bugs in the bug reporting boxes and kept them until the vector control personnel visited to collect the bugs. All of the captured bugs were transported to the vector control unit office at the departmental capital.

The follow-up stage was composed of data analysis and institutional response. The vector control unit taxonomically identified all of the reported bugs and put the data in a digital database. The vector control personnel visited the homes that were reportedly infested and their neighbours' homes for a man-hour entomological investigation, delivery of prizes and insecticide spraying. Spraying activities targeted (i) all of the existing houses in the community infested with $R$. prolixus and (ii) houses infested with $T$. dimidiata.

Data collection and analysis - When the community inhabitants handed over the bugs to the intermediate agents, the following data were collected and recorded manually on the bug reporting forms: (i) name of the municipality and community, (ii) name of the householder, (iii) name and profession of the intermediate agent and (iv) date of bug collection and reporting. Later, all of the reported bugs and forms were collected at the vector control unit office, where the vector control personnel added the following information to the same forms: (v) name of the vector control personnel, (vi) number of Triatominae vectors by species and (vii) number of nonTriatominae bugs. These data were then registered in a digital database. During the institutional response, the vector control personnel collected the following data and then registered it in the digital database: (i) name of municipality and community, (ii) name of householder, (iii) date of the institutional response, (iv) number of vectors captured during the entomological investigation by species and (v) number of houses sprayed.
The bugs reported from other municipalities or of unknown origin were excluded from the data analysis. The reported bugs were sorted and counted by species and developmental stage (nymph or adult). All of the communities that were infested with Triatominae vectors were georeferenced and mapped using the Geographic Information System software ArcView 3.0. The intermediate agents were classified into five categories (schoolteacher, vector control personnel, staff of the $\mathrm{MoH}$ health centres/posts, staff of an NGOs or neighbour) to identify the most effective method in each community for reporting bugs to the vector control unit office. With the data from the entomological investigation that were collected as a part of the institutional response, the percentage of infested communities and houses was calculated by species.

\section{RESULTS}

Bug reports from communities - In total, the vector control unit received 669 bug reports as a result of the Chagas Week campaign in San Pedro Pinula. Table I shows the number of bugs reported by the communities. Among the 2,845 bugs reported, 205 (7.2\%) were Triatominae vectors, including $R$. prolixus, $T$. dimidiata and

\section{TABLE I}

Number of reported communities, houses and bugs as a result of "Chagas Week", municipality of San Pedro Pinula, department of Jalapa, Guatemala, 2007

\begin{tabular}{lccc}
\hline & $\begin{array}{c}\text { Communities } \\
\text { reportedly } \\
\text { infested } \\
\text { (n) }\end{array}$ & $\begin{array}{c}\text { Houses } \\
\text { reportedly } \\
\text { infested } \\
\text { Species }\end{array}$ & $\begin{array}{c}\text { Bugs } \\
\text { reported } \\
\text { (n) }\end{array}$ \\
\hline $\begin{array}{l}\text { Rhodnius prolixus } \\
\text { Nymphs }\end{array}$ & 2 & 2 & 4 \\
Adults & 1 & 2 & 3 \\
\hline Total & 2 & 4 & 7 \\
\hline $\begin{array}{l}\text { Triatoma dimidiata } \\
\text { Nymphs }\end{array}$ & 16 & 29 & 99 \\
Adults & 24 & 46 & 96 \\
\hline Total & 28 & 62 & 195 \\
\hline Triatoma nitida & & & \\
Nymphs & 2 & 2 & 2 \\
Adults & 1 & 1 & 1 \\
\hline Total & 29 & 3 & 3 \\
\hline Non-Triatominae bugs & - & - & 2,640 \\
\hline Total & & 69 & 2,845 \\
\hline
\end{tabular}

the number of reported houses and communities were counted only for Triatominae vectors. 
Triatoma nitida. Among the 71 existing communities, 68 reported bugs and 29 reported Triatominae vectors. The Chagas Week campaign detected $R$. prolixus and $T$. dimidiata in two and 28 communities, respectively. Fig.

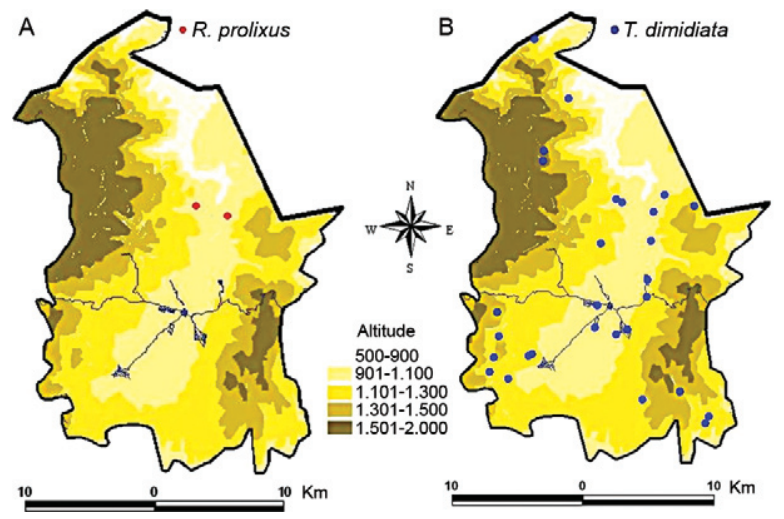

Fig. 3: map of communities infested with Rhodnius prolixus (A) and Triatoma dimidiata (B) detected by "Chagas Week" in the municipality of San Pedro Pinula, department of Jalapa, Guatemala, 2007.

\section{TABLE II}

Number of bug reports transacted by profession of intermediate agents

\begin{tabular}{lc}
\hline Profession of intermediary agents & $\begin{array}{c}\text { Bug reports transacted } \\
\mathrm{n}(\%)\end{array}$ \\
\hline Schoolteacher & $525(78.5)$ \\
Vector control personnel & $38(5.7)$ \\
Staff of MoH's health centre/post & $22(3.3)$ \\
Staff of NGO for remote health service & $20(3)$ \\
Neighbour & $1(0.1)$ \\
ND & $63(9.4)$ \\
\hline Total & $669(100)$ \\
\hline
\end{tabular}

MoH: Ministry of Health; ND: no data; NGO: non-governmental organization.
3 shows the geographical distribution of the communities that reported vector infestation. Among the total 669 bug reports, 525 (78.5\%) were reported through schoolteachers (Table II).

Institutional response to bug reports - Among the 29 communities that reported vector infestation, the vector control unit performed entomological investigations in 25 of the communities. In four of the communities, the reported houses could not be identified due to migration or demolition. Table III shows the results of the man-hour entomological investigations. $R$. prolixus was confirmed in two houses in two communities. Notably, a total of 55 specimens of $R$. prolixus (including 32 nymphs) were collected in a peridomiciliary henhouse. For $T$. dimidiata, $64 \%(16 / 25)$ of the communities and $33.8 \%(25 / 74)$ of the houses were found to be infested.

In the two communities where $R$. prolixus was confirmed by entomological investigation, the vector control personnel sprayed all existing houses with insecticide. In the 16 communities where only $T$. dimidiata or $T$. nitida was confirmed, 27 houses were sprayed.

\section{DISCUSSION}

The bug-hunting campaign was highly effective in detecting vector infestation. In the municipality of San Pedro Pinula, the communities have continued to report vectors since the traditional community-based vector surveillance was implemented in 2004. The average number of reported vectors per year was 36 in 20042006. In contrast, during Chagas Week the total number of reported vectors increased drastically to 205 (Fig. 4). The bug-hunting campaign was five-six-fold more effective than the previous reporting method regarding vector detection.

The increase in reported vectors during Chagas Week could largely depend on the stimulated community participation rather than the seasonal tendency of the vector population. Some studies in Mexico have indicated that the domiciliary population of $T$. dimidiata could increase during the hot and dry season in April-June (Dumonteil et al. 2002, Torres-Montero et al. 2012). Such seasonal variation is also observed in Jalapa, according to the number of bugs reported by the communities (Fig. 5). Seasonal

TABLE III

Number of communities and houses infested with Triatominae vectors by institutional entomological investigation as response to community bug reports, municipality of San Pedro Pinula, department of Jalapa, Guatemala, 2007

\begin{tabular}{|c|c|c|c|c|}
\hline \multirow[b]{3}{*}{ Infested with } & \multirow{2}{*}{$\begin{array}{l}\text { Communities } \\
\qquad(\mathrm{n}=25)\end{array}$} & \multicolumn{3}{|c|}{$\begin{array}{l}\text { Houses } \\
(\mathrm{n}=74)\end{array}$} \\
\hline & & Intradomiciliary & Peridomiciliary & Total \\
\hline & $\mathrm{n}(\%)$ & $\mathrm{n}(\%)$ & $\mathrm{n}(\%)$ & $\mathrm{n}(\%)$ \\
\hline Rhodnius prolixus & $2(8)$ & $1(1.4)$ & $1(1.4)$ & $2(2.7)$ \\
\hline Triatoma dimidiata & $16(64)$ & $24(32.4)$ & $2(2.7)$ & $25^{a}(33.8)$ \\
\hline Triatoma nitida & $2(8)$ & $2(2.7)$ & $0(0)$ & $2(2.7)$ \\
\hline
\end{tabular}

$a$ : in one house, $T$. dimidiata was found both in intra and peridomiciliary. 
variation may exist in San Pedro Pinula; however, Chagas Week was implemented in August, when the number of vector reports is generally low. Therefore, it is clear that the increase in the number of reported vectors during Chagas Week was not influenced by the season.

The sensitivity of vector detection rose temporarily, especially for $R$. prolixus. In the two communities that reported $R$. prolixus during Chagas Week, the traditional community-based surveillance was considered to be functioning and the vector control unit had performed repeated entomological investigations. However, R. prolixus had not been reported since 2002. The bug-hunting campaign was able to detect $R$. prolixus that was undetectable through routine vector surveillance.

From a taxonomical viewpoint, the quality of bug reports by communities is low. Among the reported bugs, only $7.2 \%$ were Triatominae vectors. This result may be attributable to a methodological reason rather than the capacity of community inhabitants to differentiate vectors from other bugs. During Chagas Week, the community inhabitants were encouraged to report any suspicious bugs and to avoid efforts to differentiate between species. Furthermore, participants who reported any bugs were given lottery tickets as an incentive for participation. This strategy led to low taxonomical quality and made the data analysis burdensome. However, it prevented community inhabitants from excluding true vectors from the bug-hunt based on misidentification of the species. It was also beneficial to measure the extent of community participation in communities where the vector was not present.

The data collected by the bug-hunting campaign were used to update the entomological map in a crosssectional manner (Fig. 3). In addition to the surprising detection of $R$. prolixus, one community was found to be infested with $T$. dimidiata for the first time. In this community, the entomological baseline survey in 2001 did not detect any vectors. Therefore, the community

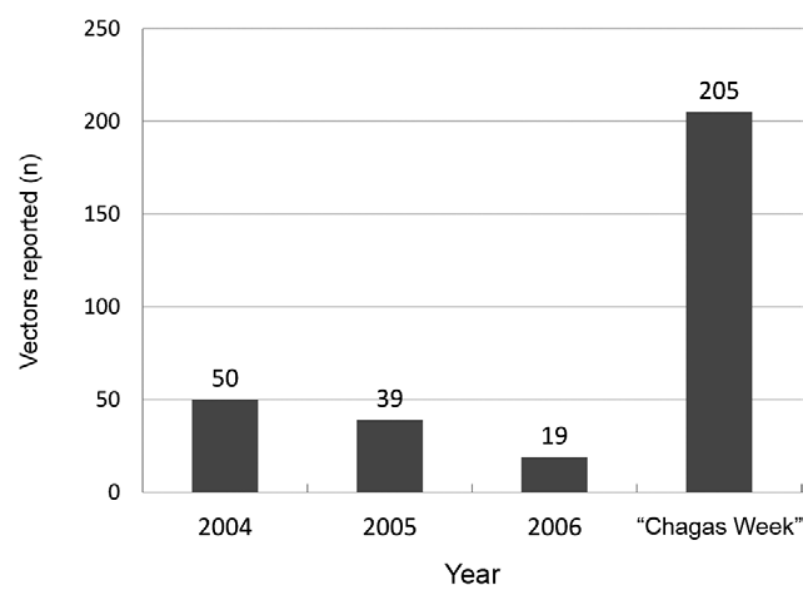

Fig. 4: comparison of vectors reported through routine communitybased surveillance (2004-2006) and bug-hunting campaign "Chagas Week" (2007) in the municipality of San Pedro Pinula, department of Jalapa, Guatemala. Source: Vector Control Unit, Ministry of Health of Guatemala. was excluded from the vector control program until three houses reported $T$. dimidiata during Chagas Week. However, the bug-hunting campaign is not suitable for standard entomological evaluation, which requires calculation of entomological indicators, such as "house infestation index" or "dispersion index" (Schofield 2001, WHO 2002). This is because the denominator of such an index (i.e., the number of houses investigated or number of villages investigated) could never be obtained through passive surveillance. The bug-hunting campaign can be used to update a vector's geographical distribution, but not for standardised entomological evaluation.

The clear and simple slogan of the bug-hunting campaign was key to raising widespread community-interest. The term "prize" strongly motivated community inhabitants to look for and report bugs. Chagas Week provided motivation for the inhabitants of the included communities to refresh their knowledge regarding Chagas disease control, which might contribute to sustainable traditional community-based vector surveillance. Another key aspect of the campaign was the involvement of primary schools as a hub of knowledge dissemination and bug collection. In San Pedro Pinula, the primary schools are distributed widely, even in remote rural communities. The schoolteachers are highly trusted in their communities and are capable of transmitting information to schoolchildren, managing the basic reporting of the collection data and collecting bugs without losing them.

In addition to raising community-interest, a festive, participative and cross-sectoral campaign such as this likely raised political attention. The departmental health director demonstrated strong commitment towards conducting the proposed Chagas Week. The departmental health office assumed full responsibility for financial support and transportation. Furthermore, the municipal government took the initiative to organise community leaders who are often political representatives of the local committees for community development.

Bug-hunting campaigns could be an economically feasible solution to sustain vector surveillance in endemic countries. Due to limited funding, the main strat-

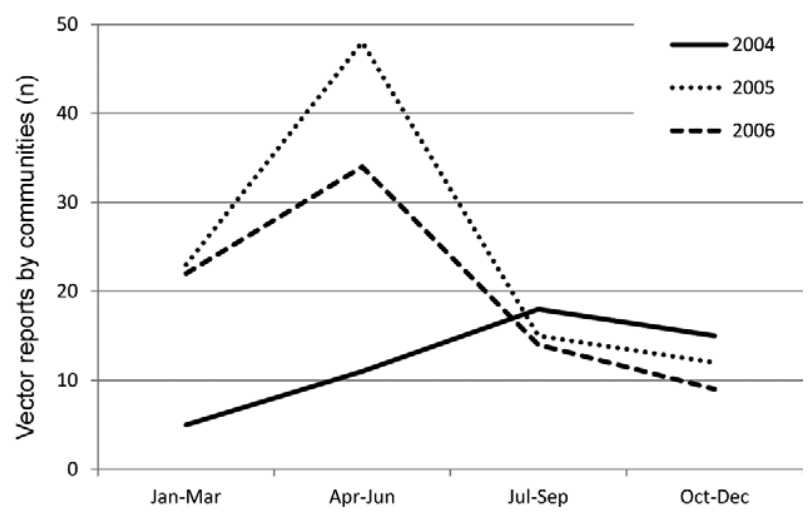

Fig. 5: seasonal tendency of vector reports by communities in the department of Jalapa, Guatemala, 2004-2006. Source: Vector Control Unit, Ministry of Health of Guatemala. 
egy for vector surveillance has shifted from institutional entomological surveys to community-based surveillance (Hashimoto \& Yoshioka 2012). However, the sensitivity of vector detection through community-based surveillance is likely to decrease without consistent institutional stimulation. For instance, the annual number of bug reports in San Pedro Pinula declined between 2004-2006 (Fig. 4). In this sense, a Chagas Week campaign could be used as an inexpensive method to stimulate community participation in bug reporting. Unfortunately, the present case study could not collect information regarding the financial burden that is required to conduct a costeffective analysis. However, the cost of Chagas Week only included the transportation of vector control personnel for two basic visits to the primary schools and the materials, including flyers and plastic bags. Therefore, it is recommended that the MoHs in endemic countries repeat the bug-hunting campaign annually.

A similar approach to the Guatemalan Chagas Week has been used routinely in Paraguay since the primary schools were involved in the National Chagas disease control program in 2001. As a part of the curriculum, the schools devote one week to the entomological search for Chagas disease vectors. In 2009, approximately 50,000 schoolchildren from 981 schools in five departments participated in the entomological search. Among the more than 70,000 houses inspected, four reported Triatoma infestans and 26 reported other species of Triatomine vectors (OPS/OMS 2011). The Paraguayan Chagas Week was recognised as a successful model for vector control (Silveira 2011). Because it successfully stimulated community participation, this initiative was recommended to be extended, adapted and modified (Abad-Franch 2011). While the Paraguayan Chagas Week found four houses with $T$. infestans among the 70,000 houses that were inspected, the Guatemalan Chagas Week identified 62 houses with $T$. dimidiata among the 9,132 existing houses. This kind of bug-hunting campaign may be much more effective in Central America, where the current target vector $T$. dimidiata repeatedly and widely infests houses even after insecticide spraying.

As discussed above, the bug-hunting campaign is an effective strategy that can be used to strengthen Chagas disease vector surveillance. Its positive impacts include (i) increasing the sensitivity of vector detection, (ii) providing information to update the vector distribution map and (iii) raising community and political attention regarding Chagas disease. These impacts also contribute to reactivating or sustaining the regular communitybased surveillance systems. The bug-hunting campaign could be implemented anywhere where the regular community-based vector surveillance must be strengthened.

The next challenge is to determine how to scale up and repeat the bug-hunting campaign. As a first step, it would be necessary to identify political spaces in which the bug-hunting campaign could be institutionalised by Central American Ministries of Health. Currently in Central America, there are political movements to establish "Chagas Day" on 9 July in remembrance of the birthday of Carlos Chagas, who discovered Chagas disease. Chagas Day was recognised and promoted by the 33th Coun- cil of Ministers of Health in Central America and in the Dominican Republic (COMISCA 2010) and by the 12th and 13th Central American initiatives for Chagas disease control (IPCA 2010, 2011). As more political will gathers, the bug-hunting campaign will become a feasible and powerful tradition for celebrating Chagas Day.

\section{ACKNOWLEDGEMENTS}

To the health personnel of the department of Jalapa, especially to Miguel Mateo, José Castañeda and Rafael Campos, for collaboration in implementing the "Chagas Week", to Jun Nakagawa, for technical advices in designing the "Chagas Week", and to Ken Hashimoto and James Romine, for reviewing this paper.

\section{REFERENCES}

Abad-Franch F 2011. Vigilancia epidemiológica y entomológica para el control de la enfermedad de Chagas con énfasis en la participación de la comunidad. In Programa regional para el control de la enfermedad de Chagas en América Latina. Iniciativa de bienes públicos regionales. Available from: chagas.zoonosis.gub.uy/index.php?option $=$ com_content $\&$ view $=$ article $\&$ id $=53$ :iniciativabi

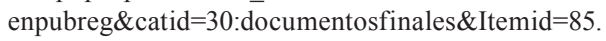

Ceballos LA, Piccinali RV, Marcet PL, Vazquez-Prokopec GM, Cardinal MV, Schachter-Broide J, Dujardin JP, Dotson EM, Kitron U, Gürtler RE 2011. Hidden sylvatic foci of the main vector of Chagas disease Triatoma infestans: threats to the vector elimination campaign? PLoS Negl Trop Dis 5: e1365.

COMISCA - Consejo de Ministros de Salud de Centroamérica 2010. Resolución de la XXXIII Reunión del Consejo de Ministros de Salud de Centroamérica y República Dominicana, 1 y 2 de diciembre de 2010, Ciudad de Belice, Belice, COMISCA, 14 pp.

Dias JCP 2009. Elimination of Chagas disease transmission: perspectives. Mem Inst Oswaldo Cruz 104 (Suppl. I): 41-45.

Dumonteil E, Gourbière S, Barrera-Pérez M, Rodriguez-Félix E, Ruiz-Piña H, Baños-Lopez O, Ramirez-Sierra MJ, Menu F, Rabinovich JE 2002. Geographic distribution of Triatoma dimidiata and transmission dynamics of Trypanosoma cruzi in the Yucatan Peninsula of Mexico. Am J Trop Med Hyg 67: 176-183.

Farr AC, Witte K, Jarato K, Menard T 2005. The effectiveness of media use in health education: evaluation of an HIV/AIDS radio campaign in Ethiopia. J Health Commun 10: 225-235.

Hashimoto K, Yoshioka K 2012. Review. Surveillance of Chagas disease. Adv Parasitol 79: 375-428.

Hill D, Carroll T 2003. Australia's national tobacco campaign. Tob Control 12: ii9-iil4.

INE - Instituto Nacional de Estadística Guatemala 2002. Lugares pobladores, XI censo nacional de población y VI de habitación 2002, INE, Guatemala, 9775 pp.

IPCA - Iniciativa de los Países de Centroamérica 2010. Acuerdos, conclusiones y recomendaciones. Décimo Segunda Reunión de la Comisión Intergubernamental de la Iniciativa de los Países de Centroamérica (IPCA) para la Interrupción de la Trasmisión Vectorial, Transfusional y Atención Médica de la Enfermedad de Chagas, 2010 Jun 16-18, San Salvador, IPCA, 6 pp.

IPCA - Iniciativa de los Países de Centroamérica 2011. Conclusiones, recomendaciones y resoluciones. Décimo Tercera Reunión de la Comisión Intergubernamental de la Iniciativa de los Países de Centroamérica (IPCA) para la Interrupción de la Trasmisión Vectorial, Transfusional y Atención Médica de la Enfermedad de Chagas. 2011 Aug 17-19, Tegucigalpa, IPCA, 5 pp. 
Johnson O 2002. Venezuela launches new campaign against dengue fever. $B M J$ 325: 512.2 .

Moncayo A, Silveira AC 2009. Current epidemiological trends for Chagas disease in Latin America and future challenges in epidemiology, surveillance and health policy. Mem Inst Oswaldo Cruz 104 (Suppl. I): 17-30.

Nakagawa J 2009. Current status and challenges of Chagas disease control initiatives in the Americas. In Advances in human vector control ACS symposium series 1014. Available from: pubs.acs. org/doi/abs/10.1021/bk-2009-1014.ch005.

Nandha B, Krishnamoorthy K 2011. Impact of education campaign on community-based vector control in hastening the process of elimination of lymphatic filariasis in Tamil Nadu, South India. Health Educ Res 27: 585.

OPS/OMS - Organización Panamericana de la Salud/Organización Mundial de la Salud 2011. Implementación de un sistema de vigilancia para el control de la enfermedad de Chagas con participación comunitaria en el Paraguay 2002-2010, OPS/OMS, Asunción, 54 pp.

Pai HH, Hong YJ, Hsu EL 2006. Impact of a short-term communitybased cleanliness campaign on the sources of dengue vectors: an entomological and human behavior study. J Environ Health 68: $35-39$.

Randolph KA, Whitaker P, Arellano A 2012. The unique effects of environmental strategies in health promotion campaigns: a review. Eval Program Plann 35: 344-353.

Schofield CJ 2001. Field testing and evaluation of insecticides for indoor residual spraying against domestic vectors of Chagas disease. Available from: https://apps.who.int/ctd/docs/whopes/ new_docs/SchofieldChagas.pdf.

Schofield CJ, Dias JCP 1999. The Southern Cone Initiative against Chagas Disease. Adv Parasitol 42: 1-27.

Schofield CJ, Jannin J, Salvatella R 2006. The future of Chagas disease control. Trends Parasitol 22: 583-588.

Shriram AN, Sugunan AP, Manimunda SP, Vijayachari P 2009. Community-centred approach for the control of Aedes spp in a periurban zone in the Andaman and Nicobar Islands using temephos. Natl Med J India 22: 116-120.
Silveira AC 2011. Transmisión vectorial de Tripanosoma cruzi y su control. In Programa Regional para el Control de la Enfermedad de Chagas en América Latina. Iniciativa de Bienes Públicos Regionales. Available from: chagas.zoonosis.gub.uy/index. php?option $=$ com_content $\&$ view $=$ article $\&$ id $=53$ :iniciativabienpu breg\&catid $=30$ :documentosfinales\&Itemid $=85$.

Silveira AC, Dias JCP 2011. The control of vectorial transmission. Rev Soc Bras Med Trop 44 (Suppl. II): 52-63.

Skarbinski J, Massaga JJ, Rowe AK, Kachur SP 2007. Distribution of free untreated bednets bundled with insecticide via an integrated child health campaign in Lindi region, Tanzania: lessons for future campaigns. Am J Trop Med Hyg 76: 1100-1106.

Terlouw DJ, Morgah K, Wolkon A, Dare A, Dorkenoo A, Eliades MJ, Vanden Eng J, Sodahlon YK, Kuile FO, Hawley WA 2010. Impact of mass distribution of free long-lasting insecticidal nets on childhood malaria morbility: the Togo National Integrated Child Health Campaign. Malar J 9: 199.

Thwing J, Hochberg N, Eng JV, Issifi S, Eliades MJ, Minkoulou E, Wolkon A, Gado H, Ibrahim O, Newman RD, Lama M 2008. Insecticide-treated net ownership and usage in Niger after a national integrated campaign. Trop Med Int Health 13: 827-834.

Torres-Montero J, López-Monteon A, Dumonteil E, Ramos-Ligonio A 2012. House infestation dynamics and feeding sources of Triatoma dimidiata in Central Veracruz, Mexico. Am J Trop Med Hyg 86: 677-682.

Wang W, MacDonald VM, Paudel M, Banke KK 2011. National scaleup of zinc promotion in Nepal: results from a post-project population-based survey. J Health Popul Nutr 29: 207-217.

WHO - World Health Organization 2002. Control of Chagas disease: second report of the WHO expert committee. WHO Tech Rep Ser 905: 120.

WHO - World Health Organization 2012. Accelerating work to overcome the global impact of neglected tropical disease. A roadmap for implementation. Available from: http://whqlibdoc.who.int/ hq/2012/WHO_HTM_NTD_2012.1_eng.pdf.

Yadón ZE, Gürtler RE, Tobar F, Medici AC 2006. Descentralización y gestión del control de las enfermedades trasmisibles en América Latina, Organización Panamericana de la Salud, Buenos Aires, $320 \mathrm{pp}$. 